\title{
Average Temperature Forecasting Based on Deli Serdang Station Using Long Short-Term Memory Model
}

\author{
Ilham Junaedi ${ }^{1}$, Endah Paramita ${ }^{1}$, Nora Valencia Sinaga ${ }^{1}$, Sri Wahyuni ${ }^{1}$, Syahrul Humaidi ${ }^{2}$ \\ ${ }^{1}$ Balai Besar Meteorologi Klimatologi dan Geofisika Wilayah 1, Indonesia \\ ${ }^{2}$ Department of Physics, FMIPA, Universitas Sumatera Utara, Medan, Indonesia
}

\section{Article Info}

Article history:

Received February 5, 2021

Revised February 20, 2021

Accepted March 14, 2021

\section{Keywords:}

Average temperature, Deliserdang Station,

Lstm.

\begin{abstract}
A B S T R A C T
An understanding of designs and gage of typical temperature joined of parameter climate and climate data for better water resource organization and orchestrating amid a bowl is uncommonly imperative. Examine climate designs utilizing ordinary and neighborhood every year typical temperatures, compare and make discernments. amid this consider, we'll analyze adjacent and conventional typical temperature data in 96031 Station backed recognition station input. the preeminent objective of this considers to appear the execution of the conventional temperature in an exceedingly single station and to predict the ordinary temperature data utilizing the Long memory Illustrate approach. bolstered the comes about of standard informatics of exploring temperature with adjacent temperature relationship, we got the appear of preparing bend, remaining plot, and thus the diffuse plot is showed up utilizing these codes. the decent execution of 96031 Station had a Mean Squared Error esteem of 0.01 and $\mathrm{R}$ squared esteem 0.98 , concerning zero will speak to superior quality of the indicator.
\end{abstract}

This is an open access article under the CC BY-SA license.

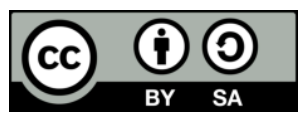

\section{Corresponding Author:}

Ilham Junaedi,

Badan Meteorologi Klimatologi dan Geofisika, Indonesia,

Jl. Ngumban Surbakti No.15, Sempakata, Kec. Medan Selayang, Kota Medan, Sumatera Utara 20131.

Email: ilham_bmg@yahoo.co.id

\section{INTRODUCTION}

The 96031 station is one of the stations within the Medan zone which conveyed to watch the climate information. As a climate station, the 96031 stations deliver climate parameter information to educate the climate in-flight route zone, environment, climate issue, and horticulture [1], [2]. One of the vital climate information in climate issues is the temperature normal. The temperature is an imperative calculate in all stages of the climate issue, and the foremost imperative climate figure influencing fire behavior. Higher temperatures cruel that heatwaves are likely to happen more frequently and final longer. Hotter temperatures can moreover lead to a chain response of other varieties around the world [3], [4]. That's since expanding discussion temperature too influences the seas, climate designs, snow and ice, and plants and creatures. In this think about, we centered to assess the time-series of normal temperature collected from 96031 stations in Meteorology, Climatology and Geophysics Territorial 1, North Sumatera, Indonesia.

Long Short-Term Memory (LSTM) networks are a substantial branch of Recurrent Neural Networks (RNN), capable of learning long-term territories [5], [6]. LSTM is a model approach to solved some forecast issues. As a type of recurrent neural network, LSTM can learn the order dependence between items in a sequence. It also had the potential of being able to learn the context required to make predictions in time series forecasting problems, rather than having this context prespecified and fixed [7], [8] 
The most objective of this consider to analyze middle factors, assess and anticipate the timeseries of normal temperature from 2008 until 2020 by utilizing the Long Short-Term Memory (LSTM) Demonstrate. The models were tried utilizing climate time arrangement information at each station which collected and compares the Root Cruel Square Mistake (RMSE) come about from the LTSM show. The comes about of this test appear that the LSTM demonstrate with/or without middle of the road variable has way better execution in case the time arrangement were accessible.

\section{DATA AND METHOD}

For this study, we utilized temperature data from the climate catalog of the Meteorology, Climatology, and Geophysics Regional I. The recorded temperature data was observed from 2008 to 2020 , with the category of the average temperature on the Medan City as observed of 96031 stations. The selection of temperature series data provides a solid basis for evaluating the performance of observed that have been installed and reviewed in previous reports. The 96031station located with latitude and longitude coordinates are 3.61, 98.78. In this case, we focused on analyst the temperature data as time series recorded from each station in the Medan area and using LSTM to train, test, and predict the time series as a previous study [5]-[7].

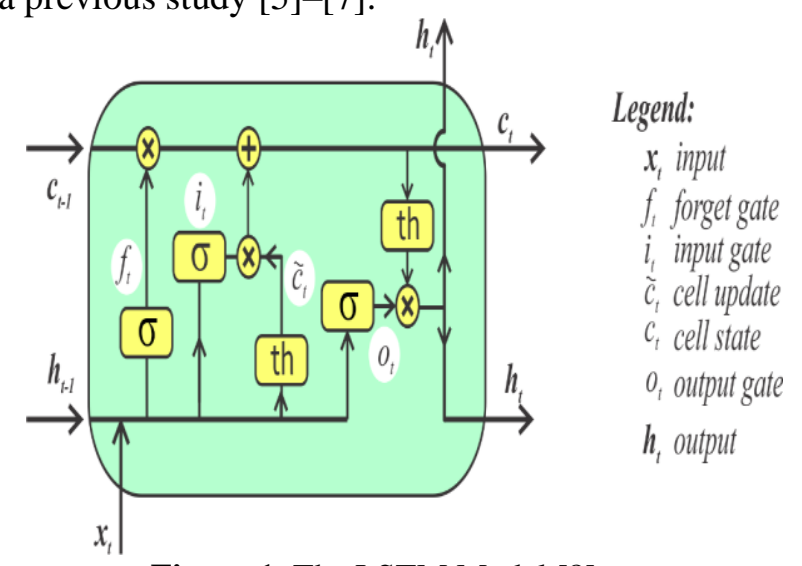

Figure 1. The LSTM Model [8]

In figure 1, as a brief depiction, the input of the LSTM cell could be a time arrangement set of information $\mathrm{x}$ that experiences a few sigmoid actuation doors $\sigma$. Each entryway calculates a certain work to calculate the cell states. What we are given is as it were an awfully brief clarification of how LSTM works. For more data with respect to LSTM, it is still partway better to require a lesson on profound learning to advance get it the concepts.

The LSTM cell comprises of an input door - which controls the stream of the input enactments into the memory cell, yield door which controls the yield stream of the cell actuation, and overlooks door, which channels the data from the input and past yield and chooses which one ought to be recollected or overlooked and dropped out. Other than three doors the LSTM cell contains cell upgrade which is more often than not tanh layer to be portion of the cell state. In each LSTM cell, the three factors are coming into the cell, the current input $x_{t}$, past yield $h_{t}-1$, and past cell state $\mathrm{c}_{\mathrm{t}}-1$. On the other hand, from each LSTM cell, two factors are getting out the current yield ht and the current cell state $\mathrm{c}_{\mathrm{t}}$.

In this section, you will learn about the concepts of mean squared error and R-squared. Mean squared error (MSE) is the average sum of the squared difference between the actual value and the predicted or estimated value. It is also termed as mean squared deviation (MSD) [9]. 


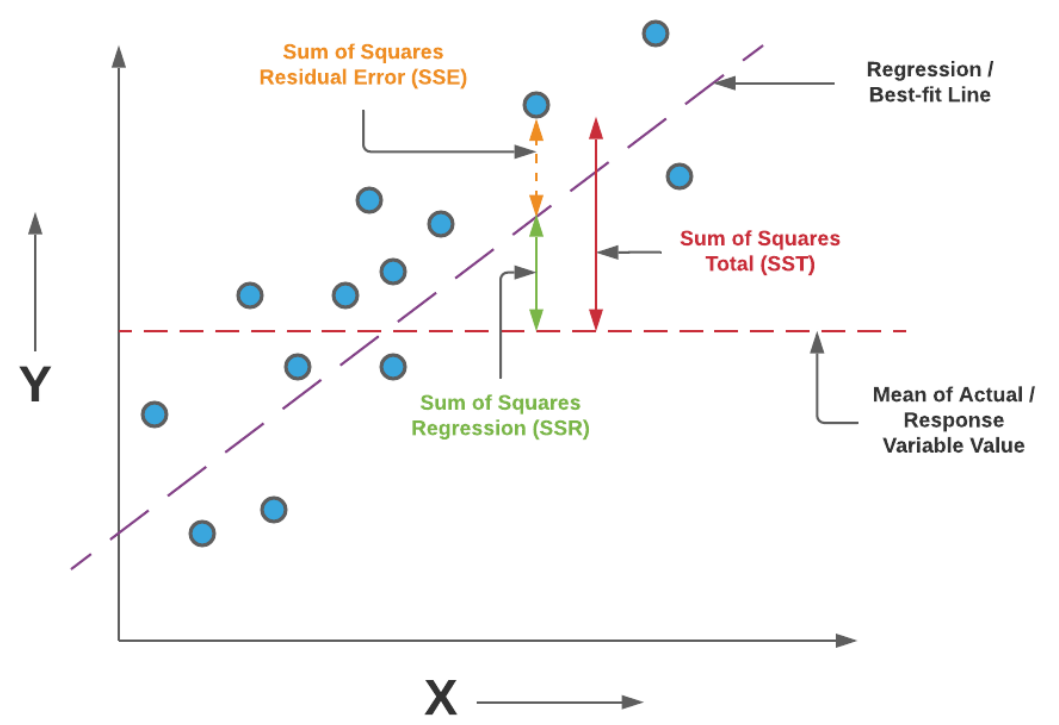

Figure 2. Diagrammatic representation for understanding R-Squared [9]

$\mathrm{R}$-Squared can also be represented using the following formula in eq.1. The diagram and note that greater the value of SSR, more is the variance covered by the regression / best fit line out of total variance (SST).

$$
R^{2}=\frac{S S T}{S S T}=\frac{\sum(\hat{y}-\bar{y})^{2}}{\sum\left(y_{i}-\bar{y}\right)^{2}}
$$

Based on the diagram and note that smaller the value of SSE, smaller is the value of (SSE/SST) and hence greater will be value of R-Squared as show in eq.2.

$$
\text { R-Squared }=1-(\text { SSE/SST })
$$

\section{RESULTS AND DISCUSSION}

The initial information of normal temperature had been computed to see that we demonstrate forecast was effective. In any case, it can be watched from the anticipated (n days) that the blunders are ordinarily from the unexpected rise or decrease within the data such as in days 350-360. But, based on the primary 75 days, the model can appropriately take after the design of the information. The visual of all information of succinct Balai Besar (96041) can be appeared in fig.3
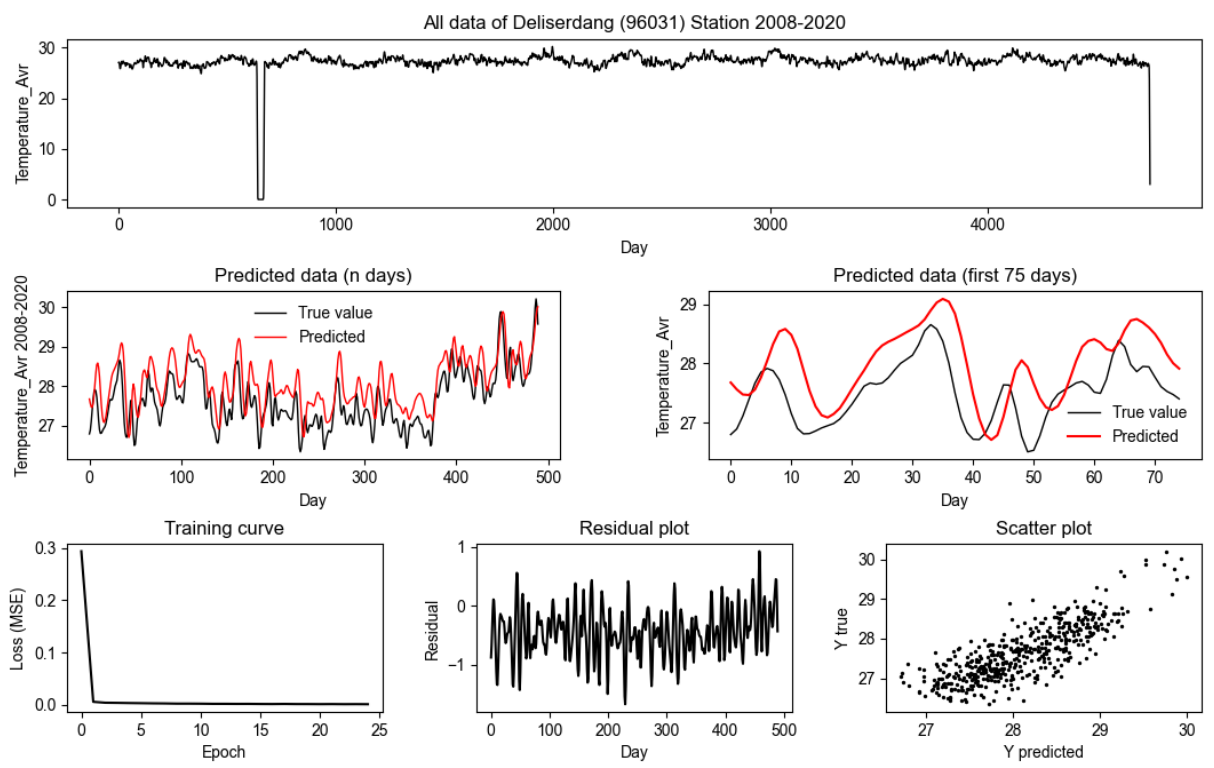

Figure 3. Stacked LSTM prediction results in 96031 Station 
The preparing bend, remaining plot, and diffuse plot are appeared utilizing these codes. The representation of 96031 stations appears the esteem near to zero will speak to way better quality of the indicator within the relapse demonstrate. It can be seen from figure 3 that the Stacked LSTM performed best compared to the types of the station. We will also see that the single-cell worked incredibly utilizing 100 input days but we found that this kind of setup was as well computationally costly. The bidirectional LSTM moreover performed more awful with more input days. Based on the series data of temperature of 96031 stations, the MSE value is 0.36 , and R2 value is 0.25 .

\section{CONCLUSION}

In this study, we found that LSTM may be a great device for foreseeing normal temperature information. Based on the representation of 96031 stations that appeared, had an esteem near to zero will speak to superior quality of the estimator/predictor (relapse show). Be that as it may, ready to see from here that there are a few things to require domestic as lessons in utilizing LSTM. To begin with, more input days does not cruel that the demonstrate will be more precise. Other than that, temperature information conditioning may, offer-assistance in making the demonstrate more accurate. Finally, indeed in spite of the fact that we haven't appeared, LSTM needs a certain sum of information to be connected. From there, able to envision that LSTM can be utilized for anticipating climate and patterns of normal temperature.

\section{REFERENCES}

[1] B. Choubin, G. Zehtabian, A. Azareh, E. Rafiei-Sardooi, F. Sajedi-Hosseini, and Ö. Kişi, "Precipitation forecasting using classification and regression trees (CART) model: a comparative study of different approaches," Environ. Earth Sci., vol. 77, no. 8, pp. 1-13, Apr. 2018, doi: 10.1007/s12665-018-7498-z.

[2] F. S.-H. \& Ö. K. Bahram Choubin, Gholamreza Zehtabian, Ali Azareh, Elham Rafiei-Sardooi, "Precipitation forecasting using classification and regression trees (CART) model: a comparative study of different approaches | SpringerLink," https://link.springer.com/article/10.1007/s12665-018-7498z? shared-article-renderer. https://link.springer.com/article/10.1007/s12665-018-7498-z?shared-articlerenderer (accessed Mar. 10, 2021).

[3] Wikepedia, "Effects of climate change - Wikipedia," https:///en.wikipedia.org/wiki/Effects_of_climate_change, 2021. https://en.wikipedia.org/wiki/Effects_of_climate_change (accessed Mar. 10, 2021).

[4] NASA, "Global Warming," https://earthobservatory.nasa.gov/features/GlobalWarming, 2010. https://earthobservatory.nasa.gov/features/GlobalWarming (accessed Mar. 10, 2021).

[5] S. Afshin, H. Fahmi, A. Alizadeh, H. Sedghi, and F. Kaveh, "Long term rainfall forecasting by integrated artificial neural network-fuzzy logic-wavelet model in karoon basin," Sci. Res. Essays, vol. 6, no. 6, pp. 1200-1208, 2011, doi: 10.5897/SRE10.448.

[6] M. I. Hutapea, Y. Y. Pratiwi, I. M. Sarkis, I. K. Jaya, and M. Sinambela, "Prediction of relative humidity based on long short-term memory network," AIP Conf. Proc., vol. 2221, no. March, 2020, doi: $10.1063 / 5.0003171$.

[7] A. G. Salman, Y. Heryadi, E. Abdurahman, and W. Suparta, "Weather forecasting using merged Long Short-Term Memory Model (LSTM) and Autoregressive Integrated Moving Average (ARIMA) Model," J. Comput. Sci., vol. 14, no. 7, pp. 930-938, 2018, doi: 10.3844/jcssp.2018.930.938.

[8] Stanford, "Understanding LSTM Networks," https://web.stanford.edu/class/cs379c/archive/2018/class_messages_listing/content/Artificial_Neural_N etwork_Technology_Tutorials/OlahLSTM-NEURAL-NETWORK-TUTORIAL-15.pdf, pp. 1-13, 2015, [Online]. Available: http://colah.github.io/posts/2015-08-Understanding-LSTMs/.

[9] A. Kumar, "Mean Squared Error or R-Squared, Data Analytics," https://vitalflux.com/mean-squareerror-r-squared-which-one-to-use/, 2020. https://vitalflux.com/mean-square-error-r-squared-which-oneto-use/ (accessed Mar. 10, 2021). 